\title{
SAÚDE MENTAL EM TEMPOS DA COVID-19: CONSTRUÇÃO DE CARTILHA EDUCATIVA COM ORIENTAÇÕES PARA O PERIODO DE PANDEMIA
}

Amanda Ouriques de Gouveia ${ }^{1}$ Herberth Rick dos Santos Silva ${ }^{1}$ José Benedito dos Santos Batista Neto' https://orcid.org/0000-0002-6874-8352

https://orcid.org/0000-0002-0778-4202

https://orcid.org/0000-0003-3228-2340

Objetivo: descrever a experiência de produção de uma cartilha informativa com o tema: Saúde Mental em Tempos de Pandemia, voltada ao público geral. Método: trata-se de um estudo descritivo, do tipo relato de experiência resultante da produção de discentes do curso de Bacharelado em Enfermagem de uma universidade pública do interior do estado do Pará, vinculada ao componente curricular - Enfermagem em Saúde Mental. Relato de Experiência: $O$ desenvolvimento da mídia aconteceu em seis etapas: 1) realização de revisão de literatura desenvolvendo a fundamentação teórica para a construção; 2) escolha do tipo de tecnologia, sendo elegida a cartilha, tendo em vista a praticidade e facilidade do acesso; 3) escolha do tipo de linguagem e recursos gráficos a serem utilizados com o intuito de atender a demanda do público-alvo e de elencar identidade visual a tecnologia; 4) elaboração da cartilha digital; 5) análise por parte da orientadora/docente; e, por fim, 6) divulgação da tecnologia em meios digitais. Considerações Finais: a construção e disseminação desta cartilha educativa foi uma viável e elucidativa forma de educação em saúde, utilizando o meio digital para levar orientações aos indivíduos quanto a medidas de manter sua saúde mental com qualidade.

Descritores: Tecnologia Educacional; Saúde Mental; Pandemias; Coronavírus.

\section{MENTAL HEALTH IN TIMES OF COVID-19: CONSTRUCTION OF EDUCATIONAL BOOKLET WITH GUIDELINES FOR THE PANDEMIC PERIOD}

Objective: Describe the experience of producing an informative booklet with the theme: Mental Health in Times of Pandemic, turned to the general public. Method: It's a descriptive study, the type of experience report resulting from the production of Bachelor degree Nursing students of a public university in the countryside of the state of Pará, linked to the curricular component - Mental Health Nursing. Experience Report: The media development took place in six stages: 1) The achievement of literature review developing the theoretical foundation for the construction; 2) choice of the type of technology, being chosen the booklet, in view of the practicality and ease of access; 3) choice of language type and graphics features to be used in order to meet the demand of the target audience and to list visual identity technology; 4) elaboration of the digital booklet; 5) analysis on the part of the guiding/docent; and finally, 6) Divulgation of the technology in digital media. Final Considerations: the construction and dissemination of this educational booklet was a viable and elucidative form of health education, using the digital medium to provide orientations to individuals as measures to maintain your mental health with quality.

Descriptors: Educational Technology; Mental Health; Pandemics; Coronavirus.

\section{SALUD MENTAL EN TIEMPOS DA COVID-19: CONSTRUCCIÓN DE FOLLETO EDUCATIVO CON DIRECTRICES PARA EL PERÍODO PANDÉMICO}

Objetivo: describir la experiencia de producir un folleto informativo con el tema: Salud mental en tiempos de pandemia, dirigido al público en general. Metodo: se trata de un estudio descriptivo, del tipo de informe de experiencia resultante de la producción de estudiantes del curso de Licenciatura en Enfermería en una universidad pública del interior del estado Pará, vinculada al componente curricular - Enfermería en Salud Mental. Informe de experiencia: El desarrollo de los medios ocurrió en seis etapas: 1) realización de una revisión de la literatura desarrollando los fundamentos teóricos para la construcción; 2) elección del tipo de tecnología, el folleto fue elegido, en vista de la practicidad y la facilidad de acceso; 3) elección del tipo de lenguaje y recursos gráficos que se utilizarán para satisfacer la demanda del público objetivo y relacionar la identidad visual con la tecnología; 4) elaboración del folleto digital; 5) análisis por parte del asesor / profesor; y por fin, 6) divulgación de tecnología en medios digitales. Consideraciones finales: la construcción y difusión de este folleto educativo fue una forma viable y explicativa de educación para la salud, utilizando el medio digital para proporcionar orientación a las personas sobre medidas para mantener su salud mental con calidad.

Descriptores: Tecnología Educacional; Salud Mental; Pandemias; Coronavirus.

'Universidade do Estado do Pará (UEPA). Tucuruí, PA.

Autor Correspondente: Herberth Rick dos Santos Silva E-mail: rick.santos.hr@gmail.com

Recebido:29/4/2020

Aceito: $21 / 5 / 2020$ 


\section{INTRODUÇÃO}

No final de dezembro de 2019, autoridades locais de saúde relataram o caso de um grupo de pacientes com pneumonia de causa desconhecida, os quais estavam epidemiologicamente ligados ao mercado de frutos do mar em Wuhan na China (1-2). A Organização Mundial da Saúde (OMS) declarou, no final de janeiro de 2020, que uma nova emergência de saúde global, havia surgido. O distrito de Wuhan, previamente citado, se tornara o epicentro de tal crise em andamento, que futuramente veio a tornar-se uma pandemia. Subsequentemente, a patologia foi nomeada como Doença do Coronavírus - 2019 (COVID-19) pela OMS, com base na família viral do patógeno causador da doença ${ }^{(2)}$.

A COVID-19 espalha-se rapidamente pela transmissão entre humanos, com um período médio de incubação de 4 dias, tendo o tempo entre o início dos sintomas de 5 a 7 dias ${ }^{(3)}$. Gotículas respiratórias e contato direto são vias de transmissão para COVID-19 4-5. Febre, tosse seca e fadiga são sintomas comuns no início da COVID-19 (5).

A COVID-19 chegou à América do Sul no dia 25 de fevereiro de 2020, quando o Ministério da Saúde (MS) do Brasil confirmou o primeiro caso. No momento atual, 29 de abril de 2020, os números oficiais do MS apontam que existem 71.886 casos confirmados e 5.017 óbitos ${ }^{(6)}$.

Não existem tratamentos antivirais ou vacinas, por ser uma nova doença viral emergente, portanto o tratamento é voltado aos cuidados para com o paciente infectado, por parte da equipe de saúde ${ }^{(7)}$.

Escassez de recursos para testes, ausência de tratamento e proteção para profissionais de saúde, imposição de medidas de saúde pública que infringem as liberdades pessoais, perdas financeiras e mensagens conflitantes das autoridades políticas, estão entre as principais estressores que, sem dúvida, influenciarão no surgimento de sofrimentos generalizados e, consequentemente, no aumento do risco de doenças psiquiátricas associadas à COVID-19, no público geral (8).

Entre os principais efeitos da pandemia está o desequilibrio da saúde mental. Segundo um estudo realizado com a equipe de saúde de Wuhan, entre 994 funcionários médicos e de enfermagem, 36,9\% apresentaram distúrbios de saúde mental abaixo do limiar, 34,4\% apresentaram distúrbios leves, 22,4\% apresentaram distúrbios moderados e 6. $2 \%$ apresentaram distúrbios graves, imediatamente após a epidemia viral ${ }^{(9)}$. Assim, a sindrome de Burnout se desenvolve relacionada diretamente às mudanças sociais, aos poucos recursos, treinamento inadequado e a falta de informações e perspectivas frente ao contexto enfrentado ${ }^{(10)}$.

Visando o oferecimento de uma atenção especial à saúde mental da população, o governo chinês adotou diversas atitudes, dentre as quais: o estabelecimento de equipes de intervenção psicológica online e o fornecimento de uma gama de serviços psicológicos a mais, como: cartilhas digitais informativas, aconselhamento psicológico hospitalar e orientações práticas de cuidado pessoal e mental nas principais redes de comunicação governamentais ${ }^{(9)}$.

Segundo o Plano Brasileiro de Preparação Para o Enfrentamento de Pandemia, dentre as atitudes a serem tomadas perante ao controle de uma pandemia, estão as ações informativas e de educação em saúde, através de informes, cartilhas e vídeos, tendo em vista o potencial disseminador, destes ${ }^{(11)}$.

Sendo assim, o presente estudo tem como objetivo descrever a experiência de produção de uma cartilha informativa com o tema: Saúde Mental em Tempos de Pandemia, voltada ao público geral (idosos e pessoas em isolamento social), equipe profissional de saúde e gestores, visando a difusão de práticas e informações preventivas ao surgimento de transtornos psicológicos.

\section{MÉTODO}

\section{Tipo de estudo}

Trata-se de um estudo descritivo, do tipo relato de experiência resultante da produção de discentes do curso de Bacharelado em Enfermagem de uma universidade pública do interior do estado do Pará, vinculada ao componente curricular "Enfermagem em Saúde Mental". Tal produção, materializa-se a partir da construção de uma tecnologia educacional, no modelo de cartilha digital que, ocupase de informar, de maneira objetiva e ilustrada, formas de preservação uma saúde mental de qualidade em meio a atual pandemia da COVID-19.

\section{Cenário do estudo}

O atual relato, fora efetivado após a proposta de realização de uma intervenção através de mídias visuais circunstanciais à pandemia da COVID-19. Os autores escolheram o modelo de produção visual, cartilha, por ser de fácil acesso e visualização, no que tange o público-alvo.

Assim, buscou-se construir uma tecnologia que viesse a concernir diversos públicos-alvo, estes: profissionais da saúde, gestores de equipes, idosos e cuidadores, pais de crianças e individuos em isolamento social.

\section{Período de realização da experiência}

As atividades de construção e divulgação da tecnologia correspondem ao período de dois meses, março e abril, de 2020. 


\section{Sujeitos envolvidos na experiência}

A construção da tecnologia foi planejada e desenvolvida por dois discentes do curso de Enfermagem, de uma universidade pública do interior do estado do Pará, com apoio, supervisão e orientação direta de uma enfermeira/ docente especializada em Saúde Mental.

\section{Aspectos éticos}

Respeitaram-se as diretrizes das resoluções 466/2012 e 510/2016 do Conselho Nacional de Saúde, sendo assim, o trabalho não foi submetido a um Comitê de Ética em Pesquisa, uma vez que trata de um relato acerca da elaboração de uma tecnologia educacional dos próprios autores, sem a utilização de dados de seres humanos. Destaca-se que para a formulação da mídia visual foram realizadas as referências bibliográficas, respeitando os critérios éticos e jurídicos que regulamentam a utilização de textos e imagens, com a preservação dos respectivos de direitos autorais.

\section{OBJETIVOS DA EXPERIÊNCIA}

O presente relato tem como objetivo a discussão e demonstração do processo criativo e de construção prática de uma tecnologia educacional, no formato de cartilha digital, tendo, esta, a temática: Saúde Mental em Tempos de Pandemia.

\section{DESCRIÇÃO DA EXPERIÊNCIA}

A tecnologia, aqui relatada, faz parte de uma proposta interventiva que surgiu a partir da visualização da condição de isolamento social, estabelecido por autoridades governamentais, e da influência desta na saúde mental de indivíduos. Fora sugerida, pela docente da Disciplina de Saúde Mental, a produção de mídias visuais que informassem medidas preventivas que atenuassem o impacto do efeito da pandemia, na saúde mental da população. A produção contara com a orientação da referida docente, que vinculou esta mídia à coordenação de comunicação institucional da Universidade e, também a encaminhou para as autoridades de saúde local, para devida difusão ao público profissional e geral.

No que diz respeito a tecnologia escolhida, fora elaborada uma cartilha digital educativa, a qual discorre sobre dicas e orientações para preservar a saúde mental em tempos de pandemia. Para que se alcancem os objetivos traçados para a solução de um problema, é importante que sejam usadas intervenções educativas, inclusive, as tecnologias educacionais, como a cartilha em questão, pois são capazes de garantir um processo educativo emancipatório ${ }^{(12)}$.

O desenvolvimento da mídia aconteceu em seis etapas: 1) realização de revisão de literatura para que se pudesse entender melhor o tema e desenvolver a fundamentação teórica para a construção; 2) escolha do tipo de tecnologia, sendo elegida a cartilha, tendo em vista a praticidade e facilidade do acesso; 3) escolha do tipo de linguagem e recursos gráficos a serem utilizados com o intuito de atender a demanda do público-alvo e de elencar identidade visual a tecnologia; 4) elaboração da cartilha digital; 5) análise por parte da orientadora/docente; e, por fim, 6) divulgação da tecnologia em meios digitais.

\section{Seleção de conteúdo para a fundamentação teórica}

No que diz respeito a primeira etapa, os acadêmicos utilizaram como referências, protocolos criados por instituições de saúde especializadas à nível mundial, isso para garantir a qualidade e veracidade das informações passadas, sendo estes, documentos protocolados pela OMS, vigente ao tema: saúde mental durante a pandemia. Além disso, foram abordados conceitos básicos de saúde mental, obtidos em artigo disponíveis em bancos de dados científicos, tal qual: a CAPES Periódicos e a SciElo Electronic Library.

\section{Escolha da tecnologia educacional a ser utilizada}

Sobre a escolha da cartilha educativa como tecnologia, temos que ela se caracteriza como uma estratégia na promoção da saúde por ser um método em que as informações possuem fácil visualização, de modo que melhora a absorção de conteúdo quando comparadas às instruções verbais isoladas ${ }^{(13)}$. Ainda, é um material que possui sua criação considerada recente, idealizada em campanhas governamentais, como forma de levar conhecimentos para públicos oriundos de diferentes contextos socioculturais e graus de escolaridade ${ }^{(14)}$.

Ainda, levando em consideração que a situação de pandemia nos exige $\circ$ isolamento social, acontece a inviabilização de ações em saúde presenciais, o que justifica ainda mais a escolha por uma educação em saúde baseada em tecnologias que podem ser disseminadas pelo meio digital.

\section{Composição da identidade visual}

Em relação a escolha de linguagem e recursos gráficos adotados, preferiu-se que fosse mais objetiva e de fácil entendimento possível, com a utilização de fontes grandes, textos curtos, e inúmeras imagens para que tornassem os materiais suficientemente didáticos. Tal escolha, justifica-se pela sua eficiência comprovada em outros estudos ${ }^{(13-14)}$.

\section{Produção da tecnologia educacional digital}

Após todo o processo anterior, iniciou-se a elaboração 
da cartilha educativa, a qual recebeu o título "Saúde Mental em Tempos de Pandemia", esta, criada digitalmente por meio de programa de computado, Microsoft Office PowerPoint 2016, tendo como formato digital "pdf". Ademais, contou com as dimensões de $19 \mathrm{~cm}$ de largura por $27,5 \mathrm{~cm}$ de altura, possuindo um total de 17 páginas e obedecendo a diagramação apresentada na figura 1 . A fonte para o texto foi Times New Roman, tamanho 24, tudo isso para garantir a boa visualização pelos indivíduos que viessem a consumi-la.

Figura 1 - Representação da diagramação seguida pela cartilha educativa "Saúde Mental em Tempos de Pandemia e Quarentena", Pará, Brasil, 2020.

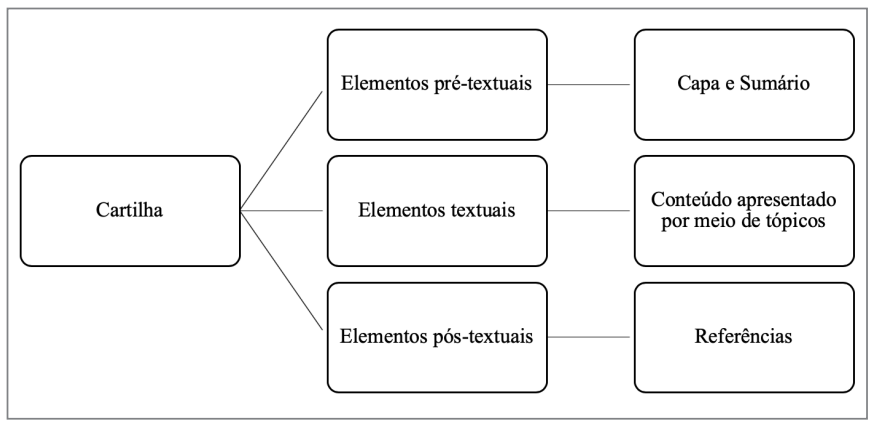

No que diz respeito aos elementos textuais da cartilha, compreendeu-se na delimitação de sete tópicos para a discussão da temática abordada, sendo que cada conteúdo possuía um objetivo específico. Os tópicos e objetivos podem ser visualizados no quadro 1 .

Quadro 1 - Conteúdo abordado pela cartilha educativa "Saúde Mental em Tempos de Pandemia e Quarentena", Pará, Brasil, 2020.

\begin{tabular}{|l|l|}
\hline \multicolumn{1}{|c|}{ Tópico } & \multicolumn{1}{c|}{ Objetivo } \\
\hline Tópico 1. O Contexto Atual; & $\begin{array}{l}\text { Abordar a atual situação que o } \\
\text { mundo está vivendo, esta, sendo a } \\
\text { pandemia da COVID-19; }\end{array}$ \\
\hline $\begin{array}{l}\text { Tópico 2. O Que Devemos } \\
\text { Fazer Como Individuos; }\end{array}$ & $\begin{array}{l}\text { Indicar atitudes que podem ser } \\
\text { tomadas dentro de nossas casas; }\end{array}$ \\
\hline $\begin{array}{l}\text { Tópico 3. O Que Devemos } \\
\text { Fazer Como Profissionais da } \\
\text { Saúde; }\end{array}$ & $\begin{array}{l}\text { Instruir medidas especificas para } \\
\text { trabalhadores da área da saúde; }\end{array}$ \\
\hline $\begin{array}{l}\text { Tópico 4. O Que Devemos } \\
\text { Fazer Como Lideres e } \\
\text { Gerentes de Equipes } \\
\text { Profissionais; }\end{array}$ & $\begin{array}{l}\text { Apresentar ações que um gerente } \\
\text { pode tomar para garantir o } \\
\text { bem-estar mental de sua equipe } \\
\text { profissional; }\end{array}$ \\
\hline $\begin{array}{l}\text { Tópico 5. O Que Devemos } \\
\text { Fazer Com as Crianças; }\end{array}$ & $\begin{array}{l}\text { Nortear formas de manter as } \\
\text { crianças entretidas e calmas no } \\
\text { periodo de quarentena; }\end{array}$ \\
\hline $\begin{array}{l}\text { Tópico 6. O Que Devo Fazer } \\
\text { Sendo Cuidador ou Idoso; }\end{array}$ & $\begin{array}{l}\text { Descrever para cuidadores } \\
\text { ou idosos ações que visam } \\
\text { ser tomadas no momento de } \\
\text { isolamento; }\end{array}$ \\
\hline $\begin{array}{l}\text { Tópico 7. O Que Devo Fazer } \\
\text { Estando em Isolamento } \\
\text { Social. }\end{array}$ & $\begin{array}{l}\text { Disseminar comportamentos que } \\
\text { contribuem para o bem-estar } \\
\text { pessoal em periodo de quarentena; }\end{array}$ \\
\hline
\end{tabular}

Por conseguinte, todas essas categorias temáticas foram direcionadas para a promoção e manutenção da qualidade da saúde mental de indivíduos durante o período de isolamento social promovido por consequência da pandemia. É interessante dizer que a cartilha fora idealizada para todos os públicos, porém com pequenos detalhes que se alteram no que tange a rotina surgida para cada sujeito.

As emergências de saúde, como o caso da pandemia da COVID-19, podem afetar a saúde, a segurança e o bemestar de indivíduos, causando, por exemplo, insegurança, confusão, isolamento emocional, estigma de comunidades, perdas econômicas, fechamento do trabalho e da escola, além de acarretarem problemas como recursos inadequados para tratamento médico. Tais especificidades, influenciam de maneira significativa na saúde mental dos indivíduos, sem que haja escolha a escolha de classes sociais, gênero ou idade ${ }^{(8)}$

Por conseguinte, feitos como esses, provocam uma série de reações emocionais (como sofrimento ou condições psiquiátricas), comportamentos não saudáveis (como uso excessivo de substâncias) e descumprimento das diretrizes públicas em pessoas que contraem a doença e na população em geral ${ }^{(8)}$.

Sendo assim, o tópico 1 da mídia introduz o leitor à cartilha, informando-os de maneira simples o porquê de o cenário de pandemia provocar ansiedade e medo nos indivíduos.

O tópico 2 traz dicas e abordagens de o que o sujeito pode fazer, individualmente, para minimizar os efeitos de medo e ansiedade promovidos pelo isolamento social e cenário de pandemia.

Partindo para uma abordagem mais especifica, aos profissionais da saúde, o tópico 3 evidencia orientações que são fundamentais para a manutenção da saúde mental no ambiente de trabalho, que no contexto atual, torna-se ainda mais desafiador e cansativo.

No que diz respeito ao tópico 4, este, é direcionado aos profissionais que atuam como líderes de equipe profissional, sendo estes, empresários, diretores e pessoas que lidam com público em geral. Também, após esses quatro primeiros tópicos, é trazido ao leitor informações, links e contatos, acerca de ajuda psicológica por meio de canais de ouvidoria gratuitos, para que possam ser utilizados se necessário, tanto pelo público geral, quanto pelo público profissional.

Voltando para uma abordagem mais ampla, o tópico 5 se direciona a todos os indivíduos que possuem crianças dentro de casa, dando orientações para mantê-las tranquilas e entretidas durante o periodo de isolamento social. Ademais, são apresentados alguns sites, aplicativos e atividades infantis para que possam ser utilizadas como ferramenta no processo de manter a calma dos pequenos. 
O tópico 6 foi criado para atender aos idosos ou indivíduos que são cuidadores de pessoas da terceira idade, que assim como as crianças, são um público que necessitam de cuidados específicos no período de isolamento social. Juntamente às orientações, foram mostrados outros aplicativos de celular e canais de vídeos digitais que podem ser utilizados, desta vez sobre práticas de exercícios físicos, elucidação de informações acerca da saúde e alimentação saudável.

Por fim, o tópico 7 funciona como um resumo dos conteúdos anteriores, mostrando mais práticas a serem seguidas em isolamento social, bem como evidencia outras mídias virtuais a serem utilizadas. Para a melhor visualização, as principais orientações foram resumidas no quadro 2 .

Quadro 2 - Resumo das principais orientações da cartilha educativa "Saúde Mental em Tempos de Pandemia e Quarentena", Pará, Brasil, 2020.

\begin{tabular}{|c|l|}
\hline Tópico & \multicolumn{1}{|c|}{ Orientações } \\
\hline 1 & $\begin{array}{l}\text { Tópico introdutório, trazendo informações gerais sobre } \\
\text { a pandemia e a influência na saúde mental; }\end{array}$ \\
\hline 2 & $\begin{array}{l}\text { Evitar excesso de informações; } \\
\text { Estabelecer rotinas; } \\
\text { Ficar em casa; }\end{array}$ \\
\hline 3 & $\begin{array}{l}\text { Apoiar os colegas de equipe; } \\
\text { Manter contato virtual com famílias e amigos, sempre } \\
\text { que possivel; } \\
\text { Descansar, alimentar-se de forma saudável; }\end{array}$ \\
\hline 4 & $\begin{array}{l}\text { Garantir boa comunicação com a equipe; } \\
\text { Realizar escalas entre os empregados, para que se evite } \\
\text { a sobrecarga; } \\
\text { Oferecer redes de apoios psicológico; }\end{array}$ \\
\hline 5 & $\begin{array}{l}\text { Desenvolver rotinas educacionais; } \\
\text { Entender o estresse das crianças; }\end{array}$ \\
\hline 6 & $\begin{array}{l}\text { Certificar o acesso adequado aos medicamentos; } \\
\text { Praticar exercícios e hobbies; } \\
\text { Apresentar informações claras e simples aos idosos; }\end{array}$ \\
\hline 7 & $\begin{array}{l}\text { Prestar atenção em suas necessidades individuais; } \\
\text { Evitar fake news; } \\
\text { Desenvolver hábitos de leitura, ouvir música, bordar, } \\
\text { etc. }\end{array}$ \\
\hline
\end{tabular}

No cenário de pandemia da COVID-19, em que não se pode ter contato pessoa-a-pessoa, a educação em saúde deve ser realizada à distância. Sendo assim, o uso de tecnologias conta com o auxílio da rede mundial de computadores, como é o caso dos aplicativos e redes sociais, a qual amplia a abordagem e dá nova característica para as práticas educativas de forma inovadora capaz de envolver grupos específicos ${ }^{(14)}$.

\section{PRINCIPAIS RESULTADOS ALCANÇADOS}

Dentre os resultados alcançados está o alcance do material ao seu público alvo. Ao ser vinculado a disciplina institucional de Saúde Mental, o material pôde ser divulgado nos principais meios de comunicação da universidade, como também, entre docentes e discentes, alcançando assim grande público, culminando no objetivo principal de divulgação de informações. Também, neste aspecto, o material fora encaminhado as autoridades de saúde local (Secretaria Municipal de Saúde e Gerentes Hospitalares), com o intuito destes compartilharem com as equipes de saúde do município e região, como também orientá-los sobre as diversas formas de prestação de cuidados à saúde mental que estão sendo oferecidas ao público profissional de forma gratuita e online. Por fim, o material fora disponibilizado nas redes sociais da secretaria de saúde do município, onde este, pôde ser acessado pelo público-alvo geral.

\section{LIMITAÇÕES DA EXPERIÊNCIA}

A experiência relatada teve sua principal limitação no que tange a sua divulgação, pois levando em consideração as recomendações da OMS de isolamento social, o único meio de compartilhamento fora o virtual, excluindo a possibilidade de os autores distribuírem versões físicas da cartilha. Outra limitação, fora referente a quantificação do alcance da cartilha. Por ter sido difundida no meio digital, o compartilhamento e acesso se tornam isentos de quantificação, por ser de fácil envio e alta afluência.

\section{CONTRIBUIÇÕES PARAA PRÁTICA}

A contribuição desse estudo está na disponibilização de materiais que visam a promoção a saúde à diversos públicos. Em períodos de pandemia, a visualização das necessidades e sofrimento psicológico tendem a ser pouco visados, quando em comparação a patologia em questão, no atual contexto, à COVID-19 (9). Portanto, a prestação do fornecimento de informações úteis, conhecimento científico no âmbito da saúde mental e divulgação dos meios de prestação atendimento psicológico, surge como uma prática não só humanitária, mas também, profissional de promoção e educação em saúde, práticas essas que são indispensáveis para a estruturação do bem-estar geral e na atuação do profissional enfermeiro. A dimensão educativa é inerente aos processos de trabalho em saúde, e deve ser vista como um meio para a mudança/transformação de determinada situação ${ }^{(15)}$.

\section{CONSIDERAÇÕES FINAIS}

O período de pandemia da COVID-19 exige o isolamento social como uma medida preventiva para a disseminação do vírus. Sendo assim, práticas de educação em saúde presenciais, como palestras, tornam-se inviáveis, instigando os profissionais da saúde a desenvolverem formas para que possam ajudar no combate. A partir disso, a construção e disseminação desta cartilha educativa foi uma viável e elucidativa forma de educação em saúde, utilizando o

172 | Enferm. Foco 2020; 11 (1) Especial: 168-173 
meio digital para levar orientações aos indivíduos quanto a medidas de manter sua saúde mental com qualidade.

CONTRIBUIÇÕES DOS AUTORES: Amanda Ouriques de Gouveia contribuiu com a concepção, desenho do estudo, revisão crítica e revisão final do manuscrito. Herberth Rick dos Santos Silva e José Benedito dos Santos Batista
Neto contribuíram com a concepção, desenho do estudo e interpretação dos dados e redação do manuscrito.

AGRADECIMENTOS: Agradecemos à Universidade do Estado do Pará (UEPA) pelo apoio na divulgação da cartilha digital em suas redes sociais e site institucional, o que contribuiu para a democratização do acesso às informações.

\section{REFERÊNCIAS}

1. Wu D, Wu T, Liu Q, Yang Z. The SARS-CoV-2 outbreak: What we Know. International J Infect Dis [Internet]. 2020 [cited 2020 Apr 18]; 94:44-48. Available from: https://www.sciencedirect.com/science/article/pii/S1201971220301235.

2. Yuen K, Ye Z, Fung S, Chan C, Jin D. SARS-CoV-2 and COVID-19: The most important research questions. Cell Biosci [Internet]. 2020 [cited 2020 Apr 18]; 10(40):1-5. Available from: https://cellandbioscience.biomedcentral.com/ articles/10.1186/s13578-020-00404-4\#citeas.

3. Guan W, Ni Z, Hu Y, Liang W, Ou C, He J, et al. Clinical characteristics of Coronavirus Diasease 2019 in China. N Engl $\mathrm{J}$ Med [Internet]. 2020 [cited 2020 Apr 19]; 382:1708-1720. Available from: https://www.nejm.org/doi/10.1056/NEJMoa2002032.

4. Huang C, Wang Y, Li X, Ren L, Zhao Z, Hu Y, et al. Clinical features of patients infected with 2019 novel coronavirus in Wuhan, China. The Lancelet [Internet]. 2020 [cited $2020 \mathrm{Apr}$ 19]; 395(10223):497-506. Available from: https://www.thelancet.com/journals/lancet/article/PIISO140-6736(20)301835/fulltext.

5. Lima DLF, Dias AA, Rabelo RS, Cruz ID, Costa SC, Nigri FMN, et al. COVID-19 in the State of Ceará: behaviors in the arrival of the pandemic. Cien Saude Colet [Internet] 2020 [Cited 2020 Apr 2019]; 25(5):1575-1586. Available from: https://www.scielo.br/scielo.php?script=sci_arttextEpi$d=$ S1413-81232020000501575\&lng=en\&nrm=iso\&tlng=en.

6. Ministério da Saúde (BR). [Internet]. Coronavirus Brasil; 2020 [cited 2020 Apr 19]. Available from: https://COVID.saude.gov.br/.

7. Shang W, Yang Y, Rao Y, Rao X. The outbreak of SARS-CoV-2 pneumonia calls for viral vacines. NPJ Vaccines [Internet]. 2020 [cited $2020 \mathrm{Apr}$ 19]; 5(18):1-3. Available from: https:// www.nature.com/articles/s41541-020-0170-0\#further-reading.

8. Pfefferbaum B, North CS. Mental Health and the COVID-19 Pandemic. N Engl J Med [Internet]. 2020 [cited 2020 Apr 27]. Available from: https://www.nejm.org/doi/full/10.1056/NEJMp2008017.
9. Kang L, Ma S, Chen M, Yang J, Wang Y, Li R, et al. Impact on mental health and perceptions of psychological care among medical and nursing staff in Wuhan during the 2019 novel coronavirus disease outbreak: A cross-sectional study. Brain Behav Immun [Internet] [Preprint]. 2020 [cited 2020 Apr 27]. Available from: https://www.sciencedirect.com/ science/article/pii/S0889159120303482?via\%3Dihub.

10. Ministério da Saúde (BR). Plano brasileiro de preparação para enfrentamento de uma pandemia de influenza. [Internet] 2010 [cited 2020 Apr 29]; Brasília; Ministério da Saúde. Available from: http://bvsms.saude.gov.br/bvs/publicacoes/plano_brasileiro_pandemia_influenza_IV.pdf

11. Lopes CCP, Ribeiro TP, Martinho NJ. Síndrome de Burnout e sua relação com a ausência de qualidade de vida no trabalho do enfermeiro. Enferm Foco [Internet]. 2012 [cited 2020 Apr 27]; 3(2):97-101. Available from: http://revista.cofen.gov.br/index.php/enfermagem/article/view/264/151.

12. Silva STC, Carvalho MJ, Carvalho OLF. Tecnologias voltadas para a educação em saúde: o que temos para a saúde dos idosos? In: Anais II Seminário de tecnologias aplicadas a educação em saúde; 2015 oct 26-27; Salvador, Brasil. Salvador: Universidade do Estado da Bahia; 2015. p. 14-21

13. Lessa LP, Silva RKS, Rocha GA, Leal JDV, Araújo AKS, Pereira FGF. Construction of a booklet on education in the transit for adolescents. J Nurs UFPE on line [Internet]. 2018 [cited $2020 \mathrm{Abr}$ 26]; 12(10):2737-42. Avaible from: https:// periodicos.ufpe.br/revistas/revistaenfermagem/article/ view/235019/30239.

14. Martins RMG, Dias ITK, Sobreira CLS, Santana KFS, Rocha RMGS, Lopes MSV. Development of a booklet for self-care promotion in leprosy. J Nurs UFPE on line [Internet]. 2019 [cited 2020 Abr 26]; 12:e239873. Avaible from: https:// periodicos.ufpe.br/revistas/revistaenfermagem/article/ view/239873/33008

15. Simonetti SH, Massa VC, França JID. Método educativo convencional e inovador para o aprendizado no usuário de anticoagulação oral. Enferm Foco [Internet] 2017 [cited 2020 Abr 27]; 8(4):03-06. Avaible from: http://revista.cofen. gov.br/index.php/enfermagem/article/view/938. 